\title{
Corpus mobile: uma descida aos confins do humano com Gonçalo M. Tavares
}

\author{
Corpus mobile: A descent into the confines of the human \\ with Gonçalo M. Tavares
}

\author{
MÁrCia SEABRA NEVES \\ Universidade Nova de Lisboa - Lisboa - Portugal
}

\begin{abstract}
Resumo: Estabelecendo um corte radical entre o homem e o animal, a tradição ocidental foinos ensinando, durante séculos, a lutar contra o animal que existe dentro de cada um de nós, reprimindo severamente a misteriosa e temível animalidade que nos habita. No entanto, o olhar interrogativo do humano sobre a sua animalidade latente ou refreada tem adquirido uma força renovada na literatura dos últimos anos. Gonçalo M. Tavares, com o seu livro animalescos (2013), faz parte desses escritores contemporâneos que cada vez mais se interrogam e refletem sobre o lado bestial do homem. Pretende-se, pois, com este estudo proceder a leitura críticointerpretativa de animalescos, de modo a acompanhar o percurso narrativo do escritor português na sua viagem aos confins do humano, durante a qual se cruzará com Francis Bacon e Gilles Deleuze, numa perscrutante auscultação da alma humana e desvendamento do espírito animal do homem.
\end{abstract}

Palavras-chave: Corpo; Movimento; Deformação; Fragmento; Animalidade

\begin{abstract}
By introducing a radical divide between man and animal, western tradition has for centuries indoctrinated us to struggle against the animal that inhabits each one of us and severely repress the mysterious and fearful animality haunting every human being. The inquisitive outlook of man on his latent or repressed animality has acquired renewed relevance in the literature published over the last few years. Gonçalo M. Tavares, especially with the fragment collection entitled animalescos (2013), can duly be included in the class of contemporary writers who enquire and reflect on man's beastly essence. In this article, we seek to provide a critical interpretation of animalescos, so as to follow the author's descent into the confines of the human. In the course of such journey he will come across Francis Bacon and Gilles Deleuze and will provide a thorough survey of the human soul while unveiling man's animal nature.
\end{abstract}

Keywords: Body; Movement; Deformation; Fragment; Animality

A Humanidade é como uma camisola de lã: pode ser despida.

(Gonçalo M. Tavares)

Os elos entre humanidade e animalidade remontam a tempos imemoriais. Com o seu enigmático e eloquente silêncio, o animal foi-se impondo, no imaginário ocidental, como uma alteridade radical para o homem. Com efeito, a contraposição ao animal constituirá, ao longo dos séculos, um dos modos mais recorrentes para definir o humano, funcionando como um espelho paradoxal no qual o homem se interroga e se projeta em busca da sua humanidade. Na verdade, a definição do humano forja-se através da negação da animalidade, ou seja, da rejeição da nossa própria natureza animal e do medo que temos de um retorno involuntário a um estado de bestialidade primeva.
Esta relação perturbante do humano com a sua animalidade tem adquirido uma projeção renovada na literatura dos últimos anos, onde cada vez mais insistentemente os escritores indagam a essência animalesca do ser humano, como acontece com Gonçalo M. Tavares, que intitulou de animalescos (2013) um dos seus mais recentes textos. Colocando a sua obra sob a tutela criativa de Francis Bacon e Gilles Deleuze, nomes que nela se cruzam numa jornada aos confins do humano, o autor disseca com bisturi expressionista o lado bestial do homem, traçando o seu percurso de desumanização num duplo movimento de queda: do humano 
ao orgânico e do orgânico ${ }^{1}$ à animalidade, por via da loucura.

1 Numa entrevista concedida a Maria João Cantinho, a propósito do volume Um Homem: Klaus Klump (2003), Gonçalo M. Tavares afirma, com lapidar desassombro, que "a Humanidade é como uma camisola de lã: pode ser despida", pois, na realidade, "não pertence ao essencial do homem", constituindo apenas uma invenção da sua linguagem e dos seus atos - não raras vezes, mais animalescos do que os dos próprios animais - para justificar a pretensa superioridade do humano sobre as outras espécies:

A ideia de que o Homem é mais moral do que um animal, uma planta ou uma pedra parece-me precipitada. E além do mais vinda dos próprios homens torna-se suspeita. É parte interessada. Em suma: o Homem pode pôr, perfeitamente, a alma e o chapéu no bengaleiro. E assim entrar numa sala mais livre, e aqui mais livre pode significar: mais disponível para a bondade ou então: mais disponível para a maldade. (apud CANTINHO, 2004, s.p.)

É precisamente esta disponibilidade do homem para a maldade e o seu retorno irracional a um estado livre e primitivo do ser que Gonçalo M. Tavares nos vai relatando no decurso das 39 vertiginosas micronarrativas que compõem animalescos, concitando o leitor a acompanhálo nessa prospeção visceral do ser humano.

O paratexto que antecede as narrativas é revelador do caráter angustiante e enigmático da obra, pressagiando um universo textual sinuoso e movediço, no qual humanidade e animalidade se confundem e diluem. Esta ambiguidade comunica-se, desde logo, ao título - animalescos - que tanto pode revestir um valor adjetival como nominal. $\mathrm{Na}$ sua valência adjetival, a palavra remete para características relativas ou próprias ao animal, antecipando um conjunto de narrativas centradas no comportamento animalesco do homem. Por outro lado, o termo reenvia para a forma nominal arabescos, ornamento de origem árabe, desenhado a partir de um entrecruzamento complexo de linhas curvas e emaranhadas. Sabendo que os arabescos islâmicos não admitem a representação de figuras humanas ou animais, a amálgama, ainda que implícita, dos termos animal e (arab)escos é cataforicamente indicial de uma escrita pictural da transgressão e do informe, em que o objeto não é animal nem humano, mas antes animalesco.

Ora, esta dissolução de fronteiras entre o homem e o animal encontra-se simbolicamente representada

\footnotetext{
Entende-se, aqui, por orgânico o corpo humano em estado de matéria pura, carcaça despojada de humanidade, ou seja, dos atributos que desde sempre distinguiram o homem do animal, a saber a razão e a linguagem.
}

na capa do livro, através de uma ilustração ("Retrato de Henrietta Moraes", 1969) do pintor inglês Francis Bacon, conhecido pela sua obsessão pela representação do corpo e pelo traço macabro e pulsional com que (des) constrói as formas anatómicas, através das quais procura problematizar os limites do humano. Convicto de que, ao conquistar e usufruir da sua própria liberdade, o ser humano liberta também a besta que se aloja em si, Bacon pinta a realidade viva do ser humano e sua misteriosa animalidade de antropoide solitário e renegado, criando uma arte transgressiva e perturbante, esteada no efeito de colisão entre o belo e o horror.

É, pois, em sintonia com este intuito realista que Bacon questiona a pintura enquanto trabalho de mimesis, propondo, em alternativa, a noção de figura, conceito aprofundado por Gilles Deleuze no seu estudo sobre o pintor inglês, intitulado Francis Bacon: Logique de la sensation. Deleuze explica que, para romper com a pulsão imitativa, Bacon isola a figura, libertando-a do caráter representativo, ilustrativo ou narrativo que assumiria, necessariamente, na sua relação com outras imagens ou objetos. As figuras de Bacon são, pois, imagens isoladas e autónomas que não contam nenhuma história, porquanto a narração é o corolário da ilustração e, por conseguinte, da representação: "Isoler est donc le moyen nécessaire le plus simple, nécessaire quoique non suffisant, pour rompre avec la représentation, casser la narration, empêcher l'illustration, libérer la Figure: s'en tenir au fait" (DELEUZE, 2002, p. 12).

O filósofo francês argumenta ainda que a figura é o corpo e que "c'est dans le corps que quelque chose se passe: il est source de mouvement" (idem, 23). Na realidade, os corpos-figuras de Bacon são apresentados como corpos espasmódicos em desordenada convulsão, que tentam fugir deles próprios por um dos seus órgãos:

Le corps s'efforce précisément, ou attend précisément de s'échapper. Ce n'est pas moi qui tente d'échapper à mon corps, c'est le corps qui tente de s'échapper lui-même par... Bref un spasme : le corps comme plexus, et son effort ou son attente d'un spasme. Peut-être est-ce une approximation de l'horreur ou de l'abjection selon Bacon. (ibidem)

Deste modo, a figura não é apenas isolada, mas também des-figurada, isto é, deformada como uma substância informe que tanto se concentra e contrai, como se prolonga e dilata, delineando corpos que derrogam qualquer lógica anatómica (idem, 25). Nestes moldes, o corpo é figura e não estrutura e, por isso, não possui rosto, mas somente cabeça, podendo até reduzir-se a ela. Deleuze distingue o rosto e a cabeça nos seguintes termos: "le visage est une organisation spatiale structurée qui recouvre la tête, tandis que la tête est une dépendance 
du corps" (idem, 27). Ora, Bacon é um pintor de cabeças sem rosto e o seu projeto enquanto retratista consiste, precisamente, em decompor o rosto para revelar a cabeça que sob ele se oculta, tornando ostensivo o espírito animal do homem:

Ce n'est pas qu'elle [la tête] manque d'esprit, mais c'est un esprit qui est corps, souffle corporel et vital, un esprit animal, c'est l'esprit animal de l'homme : un esprit-porc, un esprit-buffle, un esprit Chien, un espritchauve-souris... (ibidem)

Assim, Bacon limpa, apaga, rasura e esbate a imagem, desconstruindo e desorganizando o rosto até fazer surgir aquilo a que Deleuze chama "les traits animaux de la tête" (ibidem), que não correspondem a formas animais concretas, mas antes a espíritos que assombram essas zonas de opacidade e conferem à cabeça a sua singular individualidade. Por outras palavras, os traços de animalidade descobertos não equivalem a uma correspondência formal entre o animal e o humano, mas antes a uma zona comum de indiscernibilidade entre o homem e o animal:

[...] ce que la peinture de Bacon constitue, c'est une zone d'indiscernabilité, d'indécidabilité, entre l'homme et l'animal. L'homme devient animal, mais il ne le devient pas sans que l'animal en même temps ne devienne esprit, esprit de l'homme, esprit physique de l'homme présenté dans le miroir comme Euménide ou Destin. Ce n'est jamais une combinaison de formes, c'est plutôt le fait commun : le fait commun de l'homme et de l'animal. (idem, 28)

Neste sentido, homem e animal confundem-se, não por um processo de mutação, mas sim pela deformação do corpo pelo espírito, o espírito animal. É, pois, difícil não reconhecer nesta fusão ou indistinção uma metáfora da animalidade latente no ser humano.

Segundo Deleuze, esta zona objetiva de indiscernibilidade é representada pelo corpo enquanto carne viva - "matériau corporel de la Figure" (ibidem), em confronto com os ossos - "structure matérielle du corps" (ibidem): "on dirait que la chair descend des os, tandis que les os s'élèvent de la chair" (idem, 29). Entende-se, assim, a importância da queda na obra de Bacon, que apresenta as figuras como blocos de carne dilacerada que deslizam das suas armaduras orgânicas, num constante movimento de luta, resultando num amontoado de matéria orgânica ferida e tensa, onde não é possível a diferenciação dos corpos. Neste sentido, Deleuze afirma que a carne é a zona de aproximação entre o homem e o animal, pois ambos são carne: "La viande est la zone commune de l'homme et de la bête, leur zone d'indiscernabilité, elle est ce 'fait', cet état même où le peintre s'identifie aux objets de son horreur ou de sa compassion" (idem, p. 30). A esta luz deverá ser lida a obsessão de Bacon pela carne:

J'ai toujours été très touché par les images relatives aux abattoirs et à la viande, et pour moi elles sont liées étroitement à tout ce qu'est la Crucifixion... C'est sûr, nous sommes de la viande, nous sommes des carcasses en puissance. Si je vais chez un boucher, je trouve toujours surprenant de ne pas être là, à la place de l'animal... (apud, ibidem)

Assim, para Bacon, a cabeça é carne e não osso, pertencendo este ao rosto: "La tête est de la chaire et le masque lui-même n'est pas mortuaire, c'est un bloc de chair ferme qui se sépare des os" (idem, 31). É, deste modo, na relação cabeça-carne que se encontra a zona de indecisão objetiva do homem e do animal. Segundo Deleuze, todas as séries de cabeças de Bacon afirmam a sua identidade com a carne e, entre as mais belas, encontram-se as que são pintadas com as suas cores mais representativas, ou seja, em tons de azul e vermelho. É o caso do tríptico intitulado "Três estudos de Henrietta Moraes" (1969), recuperado pela ilustração da capa de animalescos (Fig. 1).
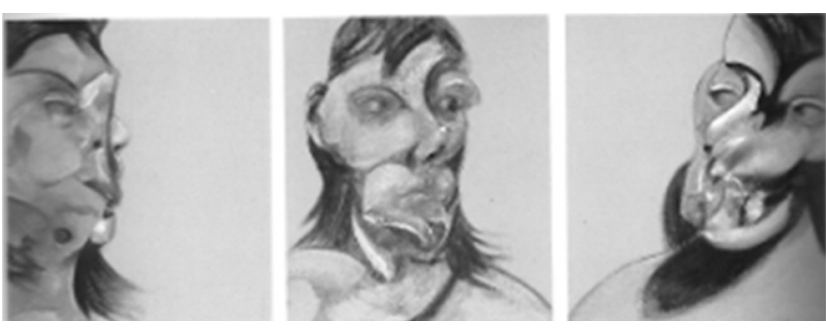

Fig. 1. Três estudos de Henrietta Moraes, 1969 (LEIRIS, 1987).

Como se torna evidente nesta série, Bacon submete os seus retratos a uma convulsionada reconfiguração facial, designadamente por meio do tratamento da figura como palimpsesto. Na realidade, o pintor apaga, raspa e risca de novo com traços intensos o rosto original, para dele desentranhar uma nova fisiologia, onde a carne em desintegração se reconstrói como corpo, numa angustiante tomada de consciência da sua verdadeira essência, reconduzível, em qualquer caso, ao espírito animal.

Ora, para que o corpo se possa moldar a todos estes movimentos da figura é necessário desorganizá-lo e desapossá-lo da sua organicidade, tornando dissonante a orquestração de partes a que chamamos organismo. Deleuze desenvolve, assim, o conceito de Corpo-semÓrgãos (CsO) para designar esse corpo anárquico 
composto de órgãos temporários e transitórios (idem, 50) figurado na obra plástica de Bacon:

[...] la Figure, c'est précisément le corps sans organes (défaire l'organisme au profit du corps, le visage au profit de la tête); le corps sans organes est chair et nerf; une onde le parcourt qui trace en lui des niveaux; la sensation est comme la rencontre de l'onde avec des Forces agissant sur le corps, [...]. Contrairement à une peinture misérabiliste qui peint des bouts d'organes, Bacon n'a pas cessé de peindre des corps sans organes, le fait intensif du corps. Les parties nettoyées ou brossées, chez Bacon, sont des parties d'organisme neutralisées, rendues à leur état de zones ou de niveaux: 'le visage humain n'a pas encore trouvé sa face...' (idem, 48)

Por outras palavras, a figura é um corpo-sem-órgãos, composto de carne e nervos, que produz e distribui intensidades pulsionais. Essas forças em contacto com a onda nervosa ou emoção vital que atravessa o corpo produzem sensações que, por sua vez, determinam os instintos. Daí a (des)organização caótica das figuras de Bacon, que não se inscrevem tanto num plano mental, regulado por uma lógica racional, mas antes num plano psiconervoso, que nos posiciona no terreno do pulsional. Neste sentido, Deleuze aponta para uma certa histeria patente nas obras de Bacon, referindose a esta imagem fragmentada e irracional do corposem-órgãos como a uma "réalité hystérique du corps" (idem, 51).

Em suma, as figuras de Bacon são seres em sensação, ou seja, que se constroem e se apreendem pelos sentidos. Com efeito, o $E u$ como sujeito deixa de existir, sendo substituído por um conjunto de linhas de força que se sobrepõem e entrecruzam numa rede disjuntiva de singularidades. Em Mille Plateaux, Deleuze e Guattari esclarecem que um $\mathrm{CsO}$ produz-se quando "les intensités passent et font qu'il n'y a plus ni moi, ni l'autre, non pas au nom d'une plus haute généralité, d'une plus grande extension, mais en vertu de singularités qu'on ne peut plus dire personnelles" (Deleuze e Guattari, 1980 : 194). Na realidade, a fragmentação do corpo aplica-se também à fragmentação do $\mathrm{Eu}$, que se desterritorializa, abrindo-se ao devir-animal :

Il faut annuler les organes, les enfermer en quelque sorte, pour que leurs éléments libérés puissent entrer dans de nouveaux rapports d'où découlent le devenir-animal et la circulation des affects au sein de l'agencement machinique. (idem, 317)

Através do pincel de Bacon, emancipado da territorialidade da figura humana, o mundo dos homens abre-se, portanto, ao devir-animal. Para isso, "il s'agit de faire corps avec l'animal, un corps sans organes défini par des zones d'intensité ou de voisinage" (idem, 335).

2 Ora, é precisamente nesta zona de vizinhança ou de indiscernibilidade entre o homem e o animal que se situa a quarta pessoa do singular que endossa a enunciação no texto de Gonçalo M. Tavares e que é, desde logo, anunciada em epígrafe pela voz de Gilles Deleuze: "quarta pessoa do singular; é ela que se pode tentar fazer com que fale" (apud TAVARES, 2013, s.p.).

Numa entrevista em que discorre sobre a vocação e os limites da filosofia ${ }^{2}$, Deleuze explica que toda a pessoa que escreve faz com que outro fale, situando esse outro num fundo anónimo e indiferenciado que não se reduz a indivíduos ou a pessoas, mas a singularidades préindividuais e impessoais:

São singularidades móveis, ladras e voadoras, que passam de um a outro, que arrombam, que formam anarquias coroadas, que habitam um espaço nômade. Há uma grande diferença entre repartir um espaço fixo entre indivíduos sedentários, segundo demarcações e cercados, e repartir singularidades num espaço aberto sem cercados e nem propriedade. O poeta Ferlinghetti fala da quarta pessoa do singular: é ela que se pode tentar fazer com que fale. (DELEUZE, 2008, p. 185)

É, portanto, no espaço aberto do seu livro que Gonçalo M. Tavares nos revela esta quarta pessoa do singular, corporizada por seres desterritorializados que não são nem indivíduos, nem pessoas e nem tão pouco animais, mas sim figuras animalescas, tão isoladas e deformadas quanto as de Francis Bacon.

A deformação patente em animalescos é, antes de mais, textual - e, mais especificamente, genológica -, visto que o escritor rompe com todos os modelos e convenções literárias, numa transgressão intencional dos padrões da narratividade, entendida como "fenómeno de sucessão de estados e de transformações, inscrito no discurso e responsável pela produção de sentido" (Reis e Lopes, 1991, p. 266). Na realidade, o autor projeta a sua própria arquitetura literária como quem desenha arabescos em torno do absurdo e do nonsense e ordenaos numa vertiginosa sucessão de fragmentos isolados de uma "negrura compacta, sem falhas", onde "o desvio [se] torna norma" (Tavares, 2013, p. 99).

\footnotetext{
2 Entrevista concedida a Jeannette Colombel e publicada na revista $L a$ Quinzaine Littéraire ( ${ }^{\circ}$ 68, março de 1969, p. 18-19), sob o título "Gilles Deleuze parle de la philosophie". O texto foi republicado numa compilação de textos e entrevistas de Deleuze, sob o título L'île déserte et d'autres textes: textes et entretiens 1953-1974 (Les éditions de Minuit, 2002), numa edição preparada por David Lapoujade. No nosso texto, citamos a tradução brasileira desta obra, organizada por Luiz B. L. Orlandi e publicada pela Editora Iluminuras.
} 
Seguindo um processo de composição análogo ao da montagem fotográfica, cada fragmento capta e transcreve situações sinistras e insólitas de seres, também eles isolados e fragmentados, em luta consigo próprios e com a sua animalidade intrínseca. Desfilam assim, ao longo das páginas de animalescos, figuras animalescas como a daquele louco que queria cozinhar outro louco "como se faz com os animais" (idem, 11), ou daquele outro que arranca a própria cabeça "pois é nela que está o inimigo que a psicanálise conseguiu colocar lá dentro" (idem, 17), ou ainda a daquela maluca que "engole moedas em vez de comprimidos e ri-se" (idem, 24). Encontramos também filhos submissos que se metamorfoseiam em porcos (idem, 43) e outros que curam a esquizofrenia do velho pai enterrando-o vivo (idem, 96), velhos que disparam com as suas espingardas para o solo a fim de acelerarem as colheitas (idem, 45), loucos que querem "abrir à força com a cabeça um buraco no solo" (idem, 72), homens que se suicidam contra uma imagem do seu pensamento (idem, 107-108), psiquiatras que endireitam os olhos dos pacientes com martelos (idem, 121), etc.

Todas estas criaturas são seres dilacerados e sem história, que lutam pela sua sobrevivência ou simplesmente por uma "questão animalesca do território" (idem, 41), numa queda constante que os projeta para zonas-limite do humano. Todos são ou se transformam em bestas, todos são animalescos e é esse traço de união que permite aglutinar coesivamente as várias ficções reunidas no livro. Nelas estas personagens são dissecadas à exaustão, recebendo um tratamento pictórico reminiscente daquele de que são objeto as figuras de Bacon.

$\mathrm{Na}$ verdade, cada um dos fragmentos de Gonçalo M. Tavares corresponde a uma espécie de expressão narrativa da pintura de Bacon. Tal como se observa nos quadros do pintor inglês, as ficções de animalescos acusam uma preterição do impulso efabulatório, com a consequente rarefação da diegese, investindo-se antes no recorte e cristalização da figura-personagem. $\mathrm{O}$ interesse dos textos não reside, assim, na sua estrutura narrativa, mas antes numa ideia de pose fotográfica que possibilita a imobilização das formas e a configuração de um teatro anatómico de figuras deformadas. Neste sentido, a estética tipologicamente indeterminada do fragmento revela-se o meio mais adequado para essa anatomização da figura e para a representação do corpo em entranhas e carne viva, uma das isotopias obsidiantes de Gonçalo M. Tavares.

Anoção do corpo como matéria movente de desordens físicas percorre todas as narrativas de animalescos, onde as figuras-personagens desafivelam a sua máscara humana e são apresentadas como corpos fragmentados, muitas vezes reduzidos a um único órgão, sinédoque emblemática da humanidade perdida. Geralmente, esse órgão é a cabeça sem rosto, composta apenas de carne e sangue, relembrando, segundo Carlos Mendes de Sousa,

o procedimento levado a cabo nos auto-retratos de Francis Bacon e em outros retratos executados pelo pintor; um processo que parte, por exemplo, do trabalho feito 'em cima' da fotografia tipo passe a qual devém na pintura um retrato deformado, uma 'cara só de carne'. (1999, p. 349)

À semelhança de Bacon, Tavares desconstrói a cara para mostrar os traços animais da cabeça, ou seja, vai limpando e rasurando a fisionomia humana das suas personagens até encontrar o irredutível espírito animal que nelas se abriga e que se manifesta nos seus comportamentos instintivos e irracionais.

Este processo de dissecação da figura encontra-se explícito logo no primeiro fragmento da obra, enunciado por um narrador heterodiegético que apresenta e descreve "um homem na rua a andar sem calças" (TAVARES, 2013, p. 9). De repente, "batem-lhe com o pau na cabeça, a cabeça abre, começa a sangrar" (ibidem). A partir desse momento, o homem passa a existir apenas como cabeça e esta transforma-se no espaço da narrativa, assumida depois por uma voz autodiegética. Pelo recurso concomitante à focalização interna, o narrador acede à cabeça e, depois, ao cérebro da personagem, numa incisiva auscultação da sua psicologia animal:

estou no meio da minha cabeça e mesmo assim começo a gritar, mesmo no centro e estás perdido, fui atirado da janela e dentro da cabeça nem tudo é claro, (...) peço que me cortem o cabelo, (...) eis o tabuleiro perfeito: a minha cabeça, a tua cabeça, dois crânios sem um único pelo (...), o que se passa lá fora não é entendido cá dentro, o cérebro une pontos, (...) mas não consigo olhar para o que está em cima de mim, em qualquer posição da cabeça a própria cabeça não se vê.. (idem, 9-10)

$\mathrm{Na}$ realidade, a deformação do corpo comparece como leitmotiv em praticamente todas as narrativas de animalescos. Num traço macabro e intuitivo, Gonçalo M. Tavares expõe a flagrante realidade das suas anatomias tumultuosas, contorcendo e esquartejando os corpos até às vísceras, numa expressão de fúria e horror. Com efeito, o leitor é surpreendido, ao longo do livro, por um amontoado de corpos violentamente mutilados, como o do médico cujo corpo é aberto a meio, retalhado e cortado "sem jeito nenhum" e "a sangue-frio" pelas suas alunas (idem, 22), ou o do louco que se auto-mutila "à custa de sangue e dor" para viver com a cabeça debaixo do solo como as avestruzes: 
a cabeça sangra e falha; e o louco bate uma vez e com uma força tremenda contra o solo de madeira e a madeira não se mexe, (...) a sua cabeça que já está a sangrar e mesmo assim (e a doer) e mesmo assim ela não para e vem uma segunda cabeçada e uma terceira. (idem, 73)

Cada uma destas figuras, nas quais se encena a brutal irrupção do espírito animal, mantém-se tragicamente humana, mas de uma humanidade que se vai progressivamente dissipando sob o efeito de forças incontroláveis que instigam uma desorganização total da estrutura orgânica do corpo incapaz de harmonizar a vontade caprichosa dos seus órgãos. Entende-se, assim, que, na sua Biblioteca, Gonçalo M. Tavares sublinhe que "o corpo não é exclusivamente um sistema de líquidos, mas também não é exclusivamente um sistema organizado de órgãos sólidos que se abraçam e combatem" (TAVARES, 2004, p. 118).

$\mathrm{O}$ autor parece, pois, subscrever as reflexões expendidas por Gilles Deleuze a propósito do seu conceito de corpo sem órgãos, subliminarmente evocado nas páginas de animalescos, onde não faltam corpos em movimento, cujos órgãos se dissolvem em massas informes que tornam fluida a fronteira que separa o humano do animal. O leitor é atropelado por homens que "avançam em grupo como se fossem uma manada, envolvidos na sua animalidade até ao focinho" (TAVARES, 2013, p. 37), sentindo-se, por vezes, atordoadamente perdido nessa zona de indiscernibilidade:

um animal louco é capaz de se pôr a morder e certos maluquinhos do hospício fazem o mesmo e portanto isto é assim: os animais copiam os homens malucos, depois os homens saudáveis entram no zoológico e copiam os gestos dos animais que copiaram os gestos das pessoas malucas e tudo, no fim, fica a quatro patas, os humanos mordem-se uns aos outros e roem a perna das mesas, está tudo baixo, tudo curvado, tudo a quatro patas, todos os animais, incluindo as gentes de qualquer língua, são obrigados às quatro patas e há no mundo como que uma descida geral, todos passam debaixo das mesas, que deixam de ser sítios para pousar objectos e passam a ser abrigos. (idem, 115)

Este excerto, semelhante a tantos outros de animalescos, permite deduzir que Gonçalo M. Tavares expõe a realidade esquizofrénica dos corpos sem órgãos como metáfora da degradação do humano em animalidade, imposta pela loucura, que se apossa dos homens e desequilibra o mundo. É, pois, a loucura que desterra o homem para essa zona comum de indecisão, vizinhança ou indiscernibilidade entre o animal e o humano, fazendo com que a humanidade regrida a um estado primitivo e bestial do ser.
3 Em Mille plateaux, Deleuze e Guattari citam como experiências de desorganização do corpo os casos do paranoico, do esquizofrénico, do masoquista, do drogado, entre outros (1980: 185-195). São precisamente as vozes destes loucos e esquizofrénicos que se fazem ouvir em animalescos, em cujos relatos o leitor rapidamente se desorienta numa espiral de delírio, ao som de orquestras compostas "unicamente por atrasados mentais, por malucos, esquizofrénicos, maníacos, psicopatas medicados ao ponto de a sua violência acabar por sair por um som fino do violino" (TAVARES, 2013, p. 63).

$\mathrm{O}$ desequilíbrio mental das personagens prolongase, desde logo, no enunciado narrativo que, subvertendo a sintaxe consensualizada, irrompe como uma torrente de palavras que se sucedem e se dispersam a um ritmo alucinante, compondo uma série de fragmentos assimétricos, tão dissonantes quanto os seres que os protagonizam. Os próprios títulos constroem-se a partir de encadeamentos aleatórios e desarticulados de palavras geralmente extraídas dos fragmentos, preparando a entrada do leitor num texto que terá que ser lido à velocidade frenética do pensamento das suas personagens, verbalizado por um narrador que oscila pendularmente entre a focalização externa e interna, numa espécie de devir animalesco.

Os textos funcionam, deste modo, como "objectos esquizofrénicos" (idem, 18) que, no mesmo instante, constroem e aniquilam, pois, como salienta Gonçalo M. Tavares, "a velocidade assimila tudo, a velocidade é como se fosse um grande estômago, a grande velocidade tudo se mistura e ao mesmo tempo nada parece acontecer" (apud Cantinho, 2004, s.p.). São múltiplos os processos técnico-discursivos mobilizados pelo escritor para conferir ao texto a sua densidade caótica: ausência total de parágrafos, fragmentos que se iniciam com minúscula ou até com sinais de pontuação e que não se fecham graficamente, sendo a pausa prosódica marcada geralmente com vírgula, repetições lexicais e estruturais, gestos e ações que se mesclam cíclica e indefinidamente, conexões e hiatos imprevisíveis, entre outros.

O narrador adota, assim, um discurso que mimetiza o ritmo nervoso do pulsional, comunicando intensidades e sensações, num registo oposto ao do cerebralismo racionalizante. O próprio escritor confirma que "O Animalescos é de outro mundo de movimentos (...) às vezes escrevo sem pensar em forma nenhuma (...) o movimento de escrita é muito veloz e orgânico. (...) Gosto da escrita instintiva" (apud Lucas, 2013, s.p.).

Ora, esta escrita instintiva e desterritorializada, radicada nas entranhas do ser, aproxima-se intencionalmente do discurso típico do esquizofrénico, apresentado por Deleuze, em La logique du sens, como 
uma linguagem talhada na profundidade dos corpos em oposição a uma linguagem de superfície:

Dans cette faillite de la surface, le mot tout entier perd son sens $(\ldots)$, c'est-à-dire sa puissance à recueillir ou à exprimer un effet incorporel distinct des actions et des passions du corps, un événement idéel distinct de sa propre effectuation présente. Tout événement est effectué, fût-ce sous une forme hallucinatoire. Tout mot est physique, affecte immédiatement le corps. (...) Le mot a cessé d'exprimer un attribut d'état de choses, ses morceaux se confondent avec des qualités sonores insupportables, font effraction dans le corps où ils forment un mélange, un nouvel état de choses. (...) Il s'agit moins dès lors, pour le schizophrène, de récupérer le sens que de détruire le mot, de conjurer l'affect ou de transformer la passion douloureuse du corps en action triomphante, l'obéissance en commandement, toujours dans cette profondeur en dessous de la surface crevée. (...) Le triomphe ne peut être obtenu maintenant que par l'instauration de mots-souffles, de mots-cris où toutes les valeurs littéraires, syllabiques et phonétiques sont remplacées par des valeurs exclusivement toniques et non écrites, auxquelles correspond un corps glorieux comme nouvelle dimension du corps schizophrénique, un organisme sans parties qui fait tout par insufflation, inspiration, évaporation, transmission fluidique. (1969, p. 107-108)

Podemos, assim, considerar que o discurso esquizofrénico que compõe a tessitura narrativa de animalescos decalca não só a fragmentação física dos corpos, como também o desmembramento do pensamento e da personalidade dessas figuras de loucos que se vão cindindo até ao paroxismo, despojando-se inteiramente da sua humanidade:

Um homem ataca na parte da frente do seu corpo, sofre na parte de trás, e esta divisão em dois assusta, torna o homem esquizofrénico, a dividir por dois, retalhado, uma folha em dois, depois em quatro, em 8 , em 16, assim vai o teu mundo, estás tão dobrado que queres falar e não se percebe. (TAVARES, 2013, p. 85)

Assim, despojados da alma racional e intelectual que os distinguia dos animais e submersos na mais profunda loucura e animalidade, todos estes seres animalescos se aproximam daquilo a que Michel Foucault, na sua monumental Histoire de la folie à l'âge classique, designou de grau zero da natureza humana: "L'animalité qui fait rage dans la folie dépossède l'homme de ce qu'il peut y avoir d'humain en lui; mais non pour se livrer à d'autres puissances, pour l'établir seulement au degré zéro de sa propre nature" (1972, p. 166).

Despir o humano da sua humanidade, como se de uma camisola de lã se tratasse, parece, em suma, ser o que pretende Gonçalo M. Tavares em animalescos. Por isso, os homens regridem a um estado primário e instintivo do ser, numa angustiante tomada de consciência da finitude das suas carcaças humanas. $\mathrm{O}$ autor expõe-nos, assim, o humano em toda a sua nudez e fragilidade, procedendo a uma penetrante sondagem do psiquismo animal do homem e dos limites da sua humanidade.

$\mathrm{Na}$ realidade, o escritor pretende firmar um compromisso ético com o mundo, obrigando-nos a refletir, com uma seriedade desencantada, sobre a parcela de instinto que ainda retemos das nossas origens e evolução, bem como a repensar a fronteira que nos separa daquela animalidade que, desde sempre, tentámos recalcar. Assim, optando pela função de desencantar, Tavares servese do horror, do absurdo e do grotesco como recursos expressivos que lhe permitem, recuperando uma expressão de Helberto Helder, converter a ficção num "instrumento para acordar as vísceras” (HELDER, 2006, p. 118).

\section{Referências}

CANTINHO, Maria João. (2004). Gonçalo M. Tavares. Disponível em: <http://www.storm-magazine.com/novodb/ index.htm>. Acesso em: 6 jan. 2014.

DELEUZE, Gilles; GUATTARI, Félix. Capitalisme et schizophrénie. Mille Plateaux. Paris: Les Éditions de Minuit, 1980.

DELEUZE, Gilles. A ilha deserta e outros textos: textos e entrevistas (1953-1974). São Paulo: Iluminuras, 2008.

DELEUZE, Gilles. Francis Bacon: Logique de la sensation. Paris: Éditions du Seuil, 2002.

DELEUZE, Gilles. Logique du sens. Paris: Les Éditions de Minuit, 1969.

FOUCAULT, Michel. Histoire de la folie à l'âge classique. Paris: Éditions Gallimard, 1972.

HELDER, Herberto. Photomaton \& Vox. Lisboa: Assírio e Alvim, 2006.

LEIRIS, Michel. Francis Bacon. Barcelona: Ediciones Polígrafa, 1987.

LUCAS, Isabel. (2013), A literatura é uma investigação que não termina. Disponível em: <http://ipsilon.publico.pt/livros/ entrevista.aspx?id=328998>. Acesso em: 6 jan. 2014.

REIS, Carlos; LOPES, Ana Cristina. Dicionário de narratologia. Coimbra: Almedina, 1991.

SOUSA, Carlos Mendes de. Clarice Lispector: figuras da escrita. 1999.708 p. Tese (Doutorado em Ciências da Literatura) - Universidade do Minho, Braga, 1999.

TAVARES, Gonçalo M. animalescos. Lisboa: Relógio d'Água, 2013.

TAVARES, Gonçalo M.Biblioteca. Porto: Campo das letras, 2004.

Recebido: 23 de abril 2014 Aprovado: 19 de agosto 2014 Contato: marcianeves@ua.pt 